Research Article

\title{
Research on Deep-Site Failure Mechanism of High-Steep Slope under Active Fault Creeping Dislocation
}

\author{
Yang Liu $\mathbb{D},{ }^{1}$ Kaiwen Zhang $\mathbb{D},{ }^{1}$ Denghang Tian $\mathbb{D D}^{1}{ }^{1}$ Liming $Q u\left(\mathbb{D},{ }^{1}\right.$ and Yang Liu ${ }^{2}$ \\ ${ }^{1}$ MOE Key Laboratory of High-speed Railway Engineering, College of Civil Engineering, Southwest Jiaotong University, \\ Chengdu 610031, China \\ ${ }^{2}$ Zhongke(Hunan) Advanced Rail Transit Research Institute, Zhuzhou 412000, China \\ Correspondence should be addressed to Liming Qu; hustqlm@163.com
}

Received 19 April 2021; Accepted 4 June 2021; Published 20 August 2021

Academic Editor: Gang Fan

Copyright (c) 2021 Yang Liu et al. This is an open access article distributed under the Creative Commons Attribution License, which permits unrestricted use, distribution, and reproduction in any medium, provided the original work is properly cited.

The reverse thrust in the deep site causes the upward propagation of stress and displacement in the overlying soil. The displacement field around the fault zone is maximum. As the spatial location becomes shallower, the soil displacement gradually becomes smaller. The deformation of the overlying soil is mainly affected by the vertical dislocation of the fracture zone. The monitoring curve showed no abrupt change value, indicating that the top surface of soil did not rupture, and only the influence of fault on the displacement transfer of the top surface of the soil. When a creeping dislocation occurs in the bottom fracture zone, the maximum principal stress of the upper boundary of the deep site is dominated by compressive stress. The maximum principal stress of the soil on both sides of the fracture zone has a maximum value, and the soil on the right side of the fracture zone has a significant compression effect. The maximum principal stress monitoring curve varies greatly, indicating the plastic failure development of soil, which is the same as the research results of the plastic failure zone in the following paper. When the bottom fracture zone starts to move, the plastic zone first appears at the junction area between the front end of the bottom fracture zone and the overlying soil. As the amount of dislocation of the fracture zone increases, the plastic zone continues to extend into the inner soil. The left and right sides of the fracture zone show tensile failure and compression failure, respectively. The development of the upper envelope curve in the plastic zone of the overlying soil satisfies the Boltzmann equation with a first-order exponential growth, while the development of the lower envelope curve satisfies the Gauss equation with a second-order exponential growth. The development curve equation of the plastic zone is verified according to the residual figures of the fitting result and the correlation parameters.

\section{Introduction}

The stability of the slope under the action of earthquake has always been a research hotspot in slope engineering disaster prevention and mitigation. Dislocation of faults during earthquake will cause huge damage to the slope, induce secondary disasters such as landslides and collapses, and cause huge economic losses [1]. With the deepening of research, slope stability gradually formed some classic calculation theories and methods, such as Bishop method [2], limit analysis method [3], and transfer coefficient method [4]. In addition, some experts and scholars have introduced new research methods for the study of slope stability, such as reliability analysis method [5] and grey theory analysis method [6]. At present, experts on slope stability research methods have done a lot of research based on model tests and finite element analysis. Sun and Yao [7] summarized the typical failure geological models of rock slopes in China and revealed the deformation failure mechanism of slopes. Soto [8] used the bottom friction theory to carry out the slope rock mass toppling deformation test to study the stability of the rock slope. Bray and Goodman [9] conducted a theoretical analysis on the bottom friction test and concluded that the rock mass is in the limit equilibrium state and the model is similar to the gravity field. Adhykary et al. [10] studied slope dumping and arc shear failure theory through centrifuge tests. Sun et al. [11] combined numerical simulation and laboratory tests to study the influence of normal fault on the Urumqi subway tunnel and found that the results of numerical 
simulation and laboratory tests were basically consistent. Ji et al. [12] developed a more complete set of laboratory test equipment based on the advantages and disadvantages of domestic and foreign test devices and verified the reliability of the device. The research results showed that the device was stable and reliable, which could provide a new model test method and research means for future research. Abe et al. $[13,14]$ used three-dimensional discrete element numerical simulation to describe the improved evolution law of fault gouge, and the results showed that the shape of fault gouge fragments and the resulting interaction determined the friction strength of the fault. Lunn et al. [15] proposed a conceptual model of fault development and numerically simulated the time and space development of geometrically complex fault linkage structures with finite element software. The results showed that the geometry was affected by three key factors: stress ratio, original joint geometry, such as contraction or expansion configuration, and the direction of principal stress. Luan et al. [16] used the strength reduction finite element method to propose a plastic zone criterion for slope instability, which was applied in actual slope engineering. Zheng et al. [17-19] used the strength reduction method to perform finite element calculations on the slope and obtained the failure process of the slope, which provided a new idea for the study of slope stability. Li et al. [20] simulated the entire process of slope instability through real examples and developed a RFPA system based on the strength reduction method.

The above-mentioned research has important guiding significance for the construction of slope engineering, but it has not obtained a reliable index for how the fault dislocation caused by earthquake affects the stability of the slope and the degree of influence. The failure mode and instability conditions of the slope under fault dislocation need to be further studied. In this paper, based on the finite element analysis software ABAQUS, a calculation model for the deep site of the high-steep slope under the dislocation of the $30^{\circ}$ dip angle fracture zone is established. From the deformation propagation of the soil, the distribution of the maximum principal stress of the overlying soil, and the development of the plastic zone during the dislocation of the fracture zone, the failure mechanism of the deep site is studied. According to the range of the plastic zone under the maximum dislocation, the distribution equation of the plastic zone is proposed in order to provide a reference for the instability mechanism of high-steep slopes under fault dislocation.

\section{Establishment of the Three-Dimensional Finite Element Model}

Fault dislocation is divided into creeping dislocation and stick-slip dislocation. The stick-slip dislocation is a kind of rapid fracture movement. The entire process takes a short time and the soil layer is not fully deformed. The creeping dislocation is a slow motion that gradually deforms over time. The creeping dislocation gives the soil time to fully deform [21]. Relevant studies have shown [22] that the creeping dislocation has more significant damage than stickslip dislocation.
The dislocation of the bottom fracture zone propagates through the deep site to the slope, which leads to the instability of the slope. This paper takes the deep site at the bottom of the slope toe as the research object to study the failure mode of the deep site under the creep of the fracture zone. Combined with previous studies on the accuracy of slope stability safety factor [23]; after many trial calculations, the overall size of the calculation model is $400 \mathrm{~m}$ (length) $\times$ $50 \mathrm{~m}$ (width) $\times 105 \mathrm{~m}$ (height), which is composed of overlying soil and bottom bedrock. The overlying soil is divided into three parts with thicknesses of $20 \mathrm{~m}, 30 \mathrm{~m}$, and $50 \mathrm{~m}$ from top to bottom. The thickness of the bottom bedrock is $5 \mathrm{~m}$, the fracture zone is located in the middle of the bedrock, whose width is $100 \mathrm{~m}$ and dip angle is $30^{\circ}$. The schematic diagram of the calculation model is shown in Figure 1.

The main failure mode of the soil under the dislocation of the fracture zone is shear failure, and the deformation during the whole process will show certain nonlinear characteristics. In order to accurately reflect the elastoplastic constitutive relationship of the stress and strain characteristics of the soil layer, the yield criterion is the Drucker-Prager yield criterion. The bottom bedrock is made of mudstone, and the overlying soil is divided into three layers and superimposed by two materials. The three layers of soil are round gravel soil, silty clay, and round gravel soil from top to bottom. The detailed soil parameters are shown in Table 1.

The calculation of the model is divided into two steps: the initial ground stress balance and the application of displacement in the bedrock fracture zone. In the initial ground stress balance calculation, the bottom and side boundary conditions of the calculation model are all normal constraints, and the upper boundary is a free boundary. The contact between the fracture zone and the overlying soil is set as frictional contact, and the initial ground stress predefined field of the soil itself is obtained by applying gravity. After the initial ground stress is balanced, the normal constraint of the fracture zone is released, and the dislocation is realized by applying the displacement load on the bottom fracture zone. The dislocation direction of the fracture zone is $X$-direction and $Z$-direction. The displacement load is mainly applied in the $Z$-direction, and the maximum displacement is $4.0 \mathrm{~m}$. In this paper, considering the influence of the most adverse conditions, the initial dislocation rate of the fracture zone is set to $0.05 \mathrm{~m} / \mathrm{s}$. After a certain displacement due to the activity of the fault zone, the dislocation rate is gradually increased until the displacement reaches $4.0 \mathrm{~m}$, and the overlying soil is fully deformed $[24,25]$. The displacement load is applied to the meshing nodes of the fracture zone, and the composite direction of the displacement load is consistent with the dip angle. The displacement loading boundary conditions are shown in Figure 2.

Since the model in this paper is an ideal homogeneous soil model, the general static analysis step is iteratively used to determine the solution of the nonlinear problem during the initial ground stress balance, which can improve the solution efficiency. After applying the displacement of the 


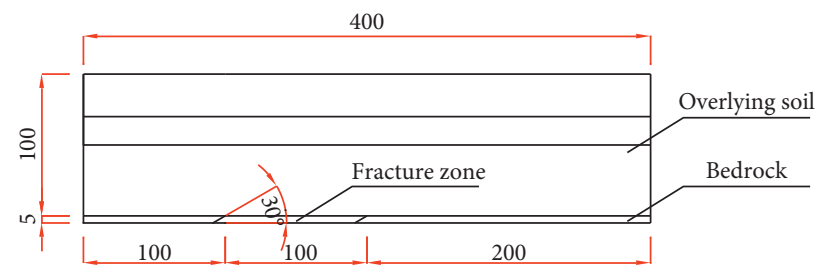

FIgURE 1: The schematic diagram of the calculation model of the deep site.

TABle 1: Soil parameters of the deep site.

\begin{tabular}{|c|c|c|c|c|c|}
\hline Soil & Density $\left(\mathrm{kg} \cdot \mathrm{m}^{-3}\right)$ & Elastic modulus (MPa) & Poisson ratio & Internal friction angle $\left({ }^{\circ}\right)$ & Cohesion $(\mathrm{kPa})$ \\
\hline Round gravel soil & 2100 & 47 & 0.25 & 40.8 & 4 \\
\hline Silty clay & 2010 & 13.6 & 0.33 & 18 & 21 \\
\hline Mudstone & 2470 & 2500 & 0.25 & - & - \\
\hline
\end{tabular}

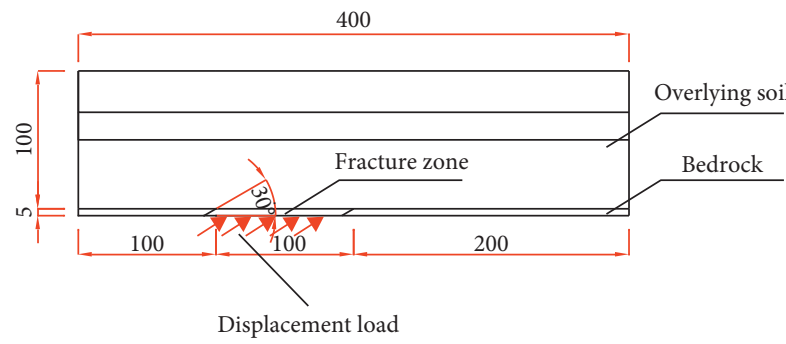

FIGURE 2: Displacement loading diagram of the bottom fracture zone.

fracture zone, the dynamic implicit algorithm can reach the convergence faster. In order to make the calculation converge faster and make the soil deformation caused by fault action closer to the actual situation, the numerical simulation adopted normal constraints around and under the surface, and no constraints were imposed on the top surface.

Due to the relatively regular shape of the calculation model, the overlying soil and the bottom bedrock are all homogeneous materials. The model is divided by eight-node hexahedral structured elements. The meshing diagram of the model is shown in Figure 3.

\section{Analysis of the Destruction Mechanism of Deep Site under Active Fault Creeping Dislocation}

The dislocation of the fracture zone at the bottom of the model is essentially the dislocation of a thrust fault, and the thrust fault is a low-angle fault with large displacement. When the fault movement, it will show significant compression and fragmentation. After the dislocation, fracture structures such as breccia and granular rock will be formed [26], and the displacement value is difficult to obtain in actual engineering. In order to obtain more accurate calculation results, the dislocation range of the fracture zone is set to $0.1 \sim 4.0 \mathrm{~m}$ in this paper, and a large number of monitoring points are selected from the displacement distribution, stress distribution, and plastic zone distribution of the soil to reveal the failure mechanism of the deep site under the fault dislocation.

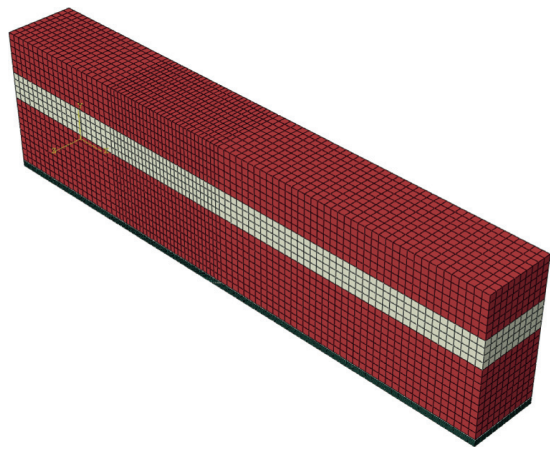

Figure 3: Meshing diagram of the calculation model.

3.1. Analysis of the Displacement Response of the Deep Site under the Creeping Dislocation of the Active Fault. The area closely related to the deep site and the slope is the upper boundary of the overlying soil. This paper selects the monitoring points of the upper boundary to study the damage of the upper soil through the displacement distribution. The displacement load of the fracture zone is a combination of two directions, so the $X$ - and $Z$-direction displacement distributions are used for analysis. Figure 4 is the vertical displacement cloud diagram when the fracture zone is displaced by $0.1 \mathrm{~m}$ and $4.0 \mathrm{~m}$, and Figure 5 is the displacement distribution curve of the monitoring points on the upper boundary of the deep site in the $X$-direction and $Z$ direction under different displacements.

When creeping dislocation occurs in the bottom bedrock fracture zone, the $X$-direction displacement curve of the overlying soil on the deep site under different displacements is centered symmetrically with a center point of $150 \mathrm{~m}$, and the center point is roughly located in the middle of the fracture zone. The deformation value on the left side of the overlying soil is negative, and the maximum value is approximately at the interface between the front of the fracture zone and the bedrock at $100 \mathrm{~m}$. The deformation value of the soil on the right is positive and the maximum deformation is roughly located at the interface between the back of the fracture zone and the bedrock at $200 \mathrm{~m}$. The distribution range of negative deformation is roughly $0 \sim 150 \mathrm{~m}$, the distribution range of positive deformation is roughly 


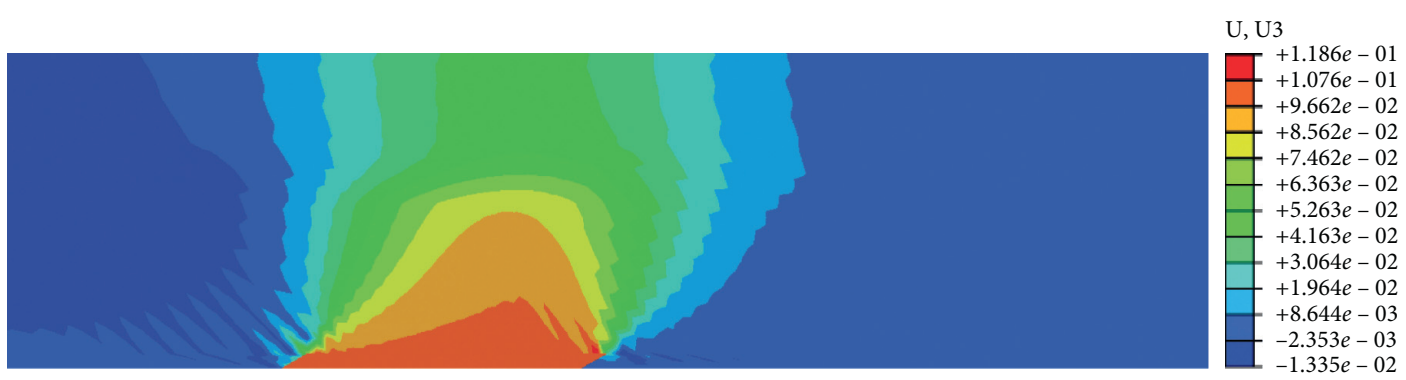

(a)

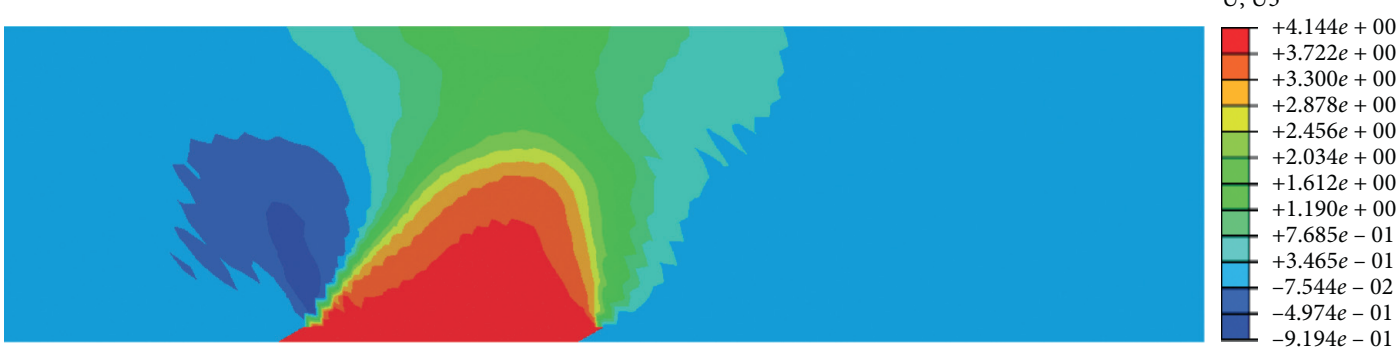

(b)

FIGURE 4: Vertical displacement cloud diagram of deep site under different displacements. (a) Vertical displacement cloud diagram when the fracture zone is displaced by $0.1 \mathrm{~m}$. (b) Vertical displacement cloud diagram when the fracture zone is displaced by $4.0 \mathrm{~m}$.

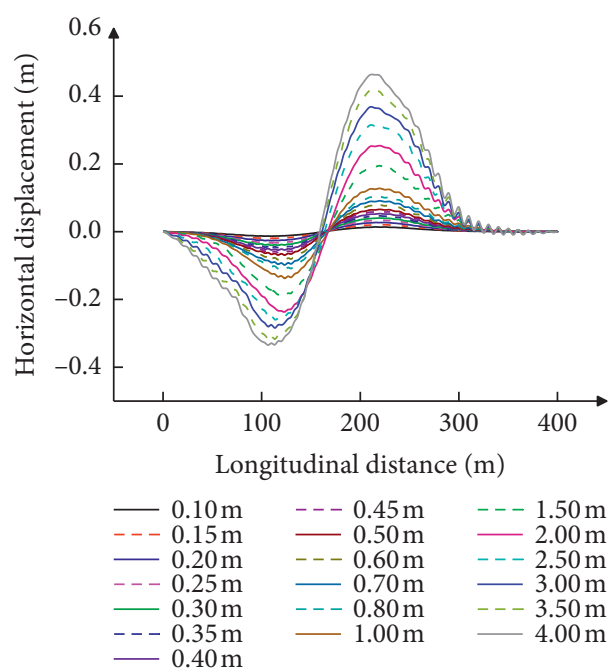

(a)

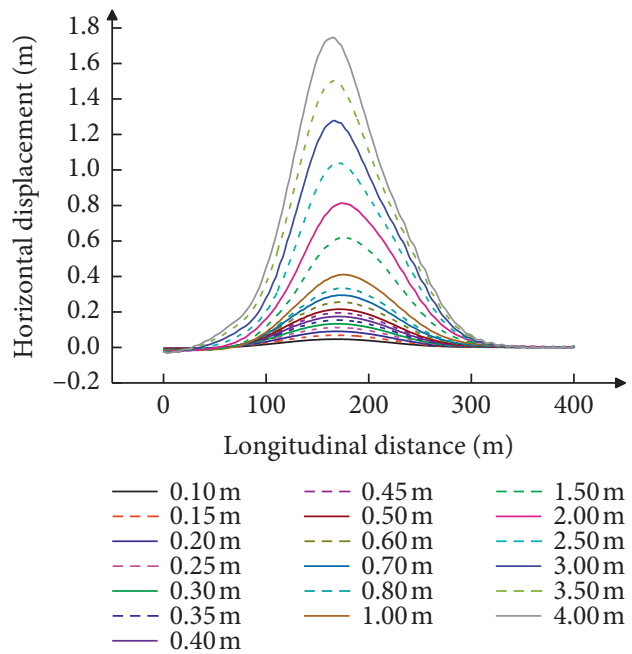

(b)

Figure 5: Displacement curve in the longitudinal direction of the deep site under different displacements. (a) $X$-direction displacement curve of the upper boundary. (b) Z-direction displacement curve of the upper boundary.

$150 \sim 300 \mathrm{~m}$, and the deep-site deformation within $300 \sim 400 \mathrm{~m}$ is basically zero. When the fracture zone is displaced by $0.1 \mathrm{~m}$, the deep-site displacement is mainly distributed in the range of $50 \sim 300 \mathrm{~m}$. With the increase of the displacement amount of the fracture zone, the displacement curve gradually rises, and the slope of the curve at the center point gradually increases.

The $Z$-direction displacement curve is symmetrically distributed with the axis of symmetry at $150 \mathrm{~m}$. The overall deformation is positive, and the maximum deformation is located at the axis of symmetry. The distribution range of the deformation along the longitudinal direction is roughly $0 \sim 300 \mathrm{~m}$, and the deformation of the soil within the range of $300 \sim 400 \mathrm{~m}$ is basically 0 , which is consistent with the distribution of the $X$-direction displacement curve along the longitudinal direction. When the fracture zone is displaced by $0.1 \mathrm{~m}$, the maximum deformation value of the overlying soil on the deep site is $0.05 \mathrm{~m}$. With the increase of the dislocation displacement of the fracture zone, the shape of the curve gradually becomes steeper, and the amount of soil deformation gradually increases. When the fracture zone is displaced by $4.0 \mathrm{~m}$, the deformation value of the upper soil is 
the largest, which is $1.75 \mathrm{~m}$, and the deformation range reaches the maximum value.

In summary, the deformation range of the overlying soil along the longitudinal length of the deep site during the dislocation of the fracture zone is roughly distributed in the $100 \mathrm{~m}$ area before and after the fracture zone, and the upper soil has the most severe deformation. The negative displacement of the $X$-direction deformation curve may be due to the forward movement of the left soil body under the pressure of the upper soil body during the dislocation process of the fracture zone. The $Z$-direction overall deformation is tensile deformation, and the $Z$-direction deformation is larger than the $X$-direction deformation under different displacement amounts. With the increase of the dislocation amount of the fracture zone, the maximum displacement in the $X$-direction at the boundary of the overlying soil layer is $0.45 \mathrm{~m}$, and the maximum displacement in the $Z$-direction is $1.75 \mathrm{~m}$. It can be inferred that the propagation of the fracture zone displacement to the overlying soil layer is mainly determined by the vertical displacement.

3.2. Analysis of the Stress Response of the Deep Site under the Creeping Dislocation of the Active Fault. For the upper boundary of the overlying soil, the maximum principal stress distribution is used to measure the damage of its surface. Figure 6 shows the maximum principal stress distribution curve along the longitudinal direction of the upper boundary of the fracture zone with different displacements.

Comprehensive analysis of the maximum principal stress distribution curve of the upper boundary in the above figure shows that the maximum principal stress of the overlying soil is dominated by compressive stress. When the fracture zone just started to move, the maximum principal stress of the soil along the longitudinal length direction increased negatively, and the compressive stress gradually increased. In the area near $100 \mathrm{~m}$, the compressive stress begins to decrease, showing a tendency of tension, but the maximum principal stress value does not show a positive value, and the soil is still in a compressed state. With the increase of the longitudinal distance, the compressive trend becomes more obvious and reaches the maximum compressive stress near $250 \mathrm{~m}$. When the dislocation amount of the fracture zone is $0.1 \sim 1.0 \mathrm{~m}$, the shape of the maximum principal stress distribution curve does not change significantly, but as the displacement amount of the fracture zone increases, the value of the maximum principal stress increases as a whole. When the fracture zone is displaced by $1.5 \mathrm{~m}$, the curve changes greatly. The maximum principal stress value of the soil in the area of 100 200 $\mathrm{m}$ appears to be a plateau, and its value does not change significantly with the increase of the displacement amount of the fracture zone, while the maximum principal stress on both sides of the fracture zone increases significantly. The fracture zone is displaced to the upper right part of the overlying soil at a dip angle of $30^{\circ}$, and the lower right area of the deep site has a significant compression effect. When the dislocation amount is $2.0 \mathrm{~m}, 3.0 \mathrm{~m}$, and $4.0 \mathrm{~m}$, it can be seen that the variation trend of the maximum principal stress curve has a great change. The analysis reason is mainly due to the plastic failure development situation caused by the influence of fault on the soil, which changes in the soft soil layer. The following will focus on the analysis of this change.

\subsection{Analysis of the Development of Plastic Zone under the} Creeping Dislocation of the Active Fault. Related research [27] shows that when calculating slope stability and studying slope instability conditions, the equivalent plastic strain penetration from the toe to the slope can be used as an important criterion for slope instability. The distribution of the plastic zone of the overlying soil layer under the dislocation of the bedrock fracture zone indicates the specific damage range of the soil and the development process of the damage. Since there are many working conditions of the model built, the working conditions with a significant development range of the plastic zone are selected for analysis and research. Figure 7 is the cloud diagrams of the development of the plastic zone of the overlying soil when the bedrock fracture zone is displaced $0.3 \mathrm{~m}, 0.6 \mathrm{~m}, 1.0 \mathrm{~m}, 2.0 \mathrm{~m}$, $3.0 \mathrm{~m}$, and $4.0 \mathrm{~m}$.

The development cloud diagrams of the plastic zone of the overlying soil under the creeping dislocation of the bedrock fracture zone show that when the bottom fracture zone starts to move, the plastic zone first appears at the boundary between the front end of the fracture zone and the overlying soil. With the increase of the displacement amount of the fracture zone, the plastic zone of the overlying soil begins to develop inside the overlying soil at an angle of $45^{\circ}$. When the fracture zone is displaced by $0.6 \mathrm{~m}$, plastic deformation occurs in the boundary area between the rear end of the fracture zone and the overlying soil, and it extends into the soil with the increase of the displacement of the fracture zone. The plastic zone at the front end of the fracture zone begins to extend inner in a horizontal direction, and the plastic strain is concentrated in the boundary area between the front end of the fracture zone and the overlying soil and gradually decreases inward in a disc-shaped during the whole process. The reason for this phenomenon may be due to the fact that the soil on the left side of the fracture zone mainly bears the tensile force, and the right side mainly bears the pressure during the dislocation process. The compressive strength of soil is much better than its own tensile strength. With the increase of displacement, the soil on the left is gradually damaged, and the soil on the right is gradually crushed. During the whole dislocation process of the bottom fracture zone, the plastic zone development law of the overlying soil is obvious. Therefore, it can be inferred that there is a certain connection between the development of the plastic strain of the overlying soil and the dislocation of the fracture zone. As the amount of fault dislocation continues to increase, the soil layer contains a soft clay layer, and a plastic failure zone develops laterally, which is mainly caused by the silty clay layer's soft texture, large cohesive force, and small friction angle, which is easy to be destroyed. 


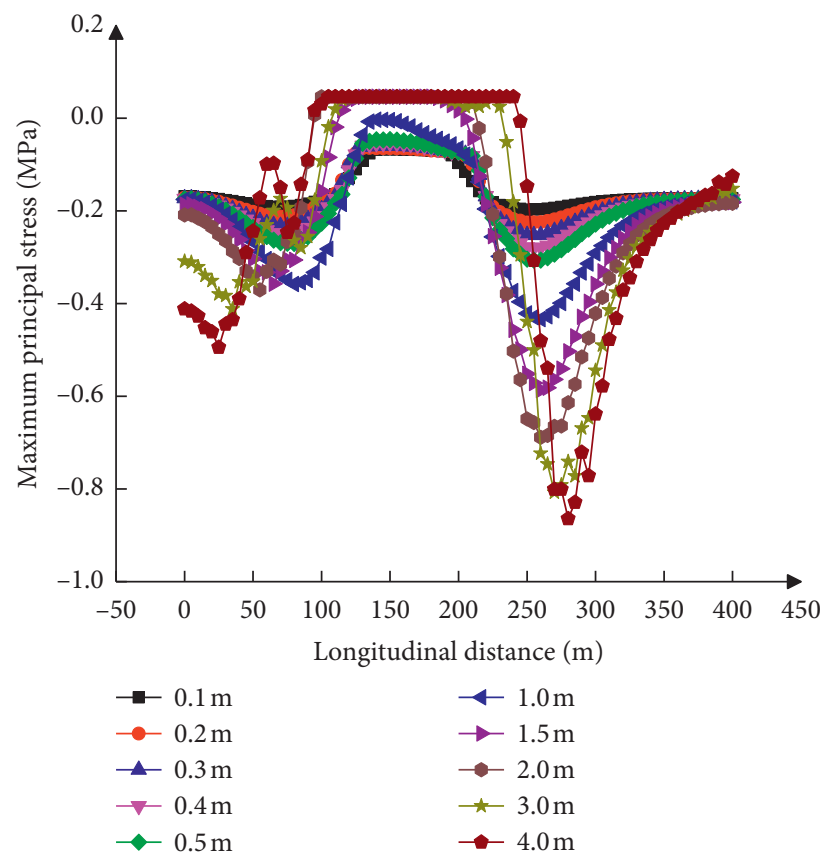

Figure 6: The distribution curve of the maximum principal stress along the longitudinal length of the upper boundary.

\section{Quantitative Analysis of the Development of Rupture Traces in Deep Site under Active Fault Creeping Dislocation}

The development of the plastic zone of the overlying soil is regular in the dislocation process of the fracture zone at the bottom of the deep site. Studying the development of the plastic zone in the dislocation process of fracture zone will provide an important reference for engineering construction and engineering disaster prevention and mitigation [28]. The study in Section 3 of this paper shows that the plastic strain develops more significantly in the area between the overlying soil and the left side of the fracture zone during the fault movement. In order to explore the development law of the plastic zone of the overlying soil, this paper establishes a calculation model for the overlying soil of the uniform round gravel soil and selects the trace of the plastic zone on the left side of the fracture zone under the displacement amount of $4.0 \mathrm{~m}$ for quantitative regularity research. Figure 8 shows the cloud diagram of the development of the plastic zone.

When the bottom fracture zone is displaced $4.0 \mathrm{~m}$, the plastic strain in the boundary area between the overlying soil and the front end of the fracture zone is more concentrated. The development area of the plastic zone is divided into an upper envelope and a lower envelope, which is divided into two parts for research.

4.1. Development Law of the Upper Envelope Curve of the Plastic Zone. When the fracture zone is displaced $4.0 \mathrm{~m}$, the development range of the plastic zone is roughly $0 \sim 50 \mathrm{~m}$. According to the approximate range of the upper envelope when the fracture zone is displaced $4.0 \mathrm{~m}$, some suitable reference points are selected and fitted to obtain the upper envelope. The fitting result is shown in Figure 9, and the fitting curve equation and related parameters are shown in Table 2.

The fitting function of the envelope curve on the plastic zone selects Boltzmann equation. Boltzmann extended the Maxwell distribution to Maxwell-Boltzmann distribution, and it has been widely used in engineering practice $[29,30]$. After bringing the data into the equation, the fitting curve formula of the envelope curve on the plastic zone is obtained:

$$
y=\frac{-83.19112}{1+e^{((x-10.40827) / 12.88084)}}+62.1508 .
$$

After the fitting curve is obtained, it is determined whether the curve has a good degree of fit according to the residuals and correlation coefficients. The residual figures of the fitting curve are shown in Figure 10.

It can be seen from the fitting curve related parameter table and the fitting curve residual graph that the correlation coefficient $R^{2}$ of the fitting curve is 0.9995 , and the fitting degree of the reference points and the upper envelope curve is better. The points in the residual graph are distributed on a horizontal band with the origin as the center, and the distribution of scattered points along the horizontal direction is the same, indicating that the residuals are random and the selected regression model is reasonable. Therefore, it can be inferred that the development of the upper envelope curve on the plastic zone of the overlying soil during the fracture zone dislocation process satisfies the Boltzmann equation and exhibits a first-order exponential growth.

4.2. Development Law of the Lower Envelope Curve of the Plastic Zone. Consistent with the research method of the 


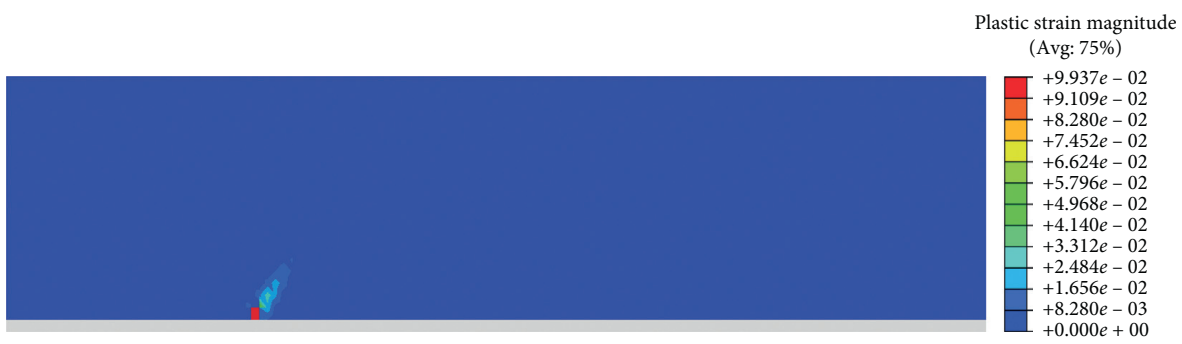

(a) Plastic strain magnitude (Avg: 75\%)

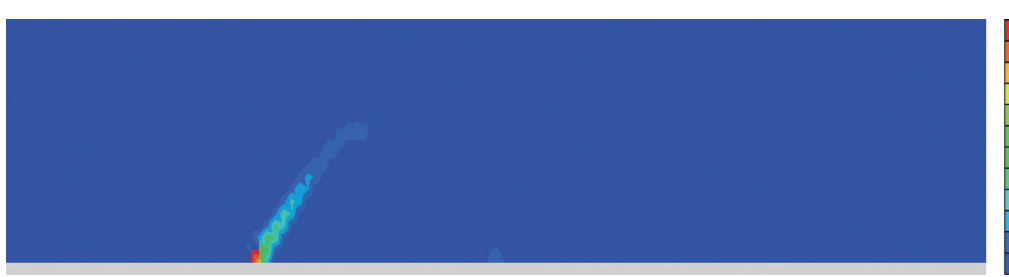

$+2.016 e-01$

$+1.848 e-01$

$1.680 e-01$

$1.512 e-01$

$1.344 e-01$

$+1.176 e-01$

1.008e-01

$6.720 e-02$

$+6.720 e-02$

$5.040 e-02$
$+3.360 e-02$

$+1.680 e-02$

$+0.000 e+00$

(b)

Plastic strain magnitude

(Avg: $75 \%$ )

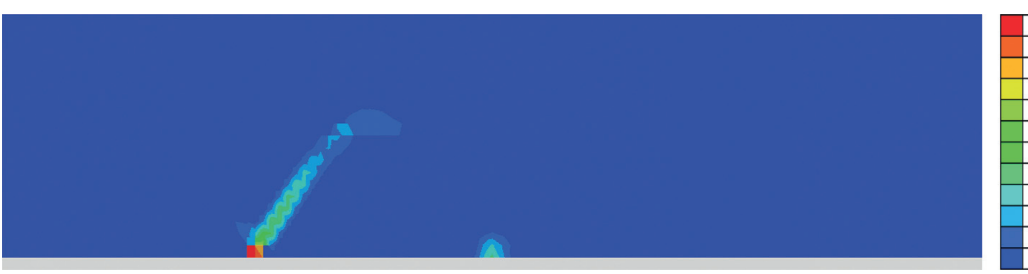

$+3.044 e-01$

$+2.791 e-01$

$+2.537 e-01$

+2.283e-01

$-.030 e-01$
$+1.776 e-01$

$+1.522 e-01$

$+1.268 e-01$

$+1.015 e-01$

$+7.611 e-02$

$+5.074 e-02$

$+2.537 e-02$

(c)

Plastic strain magnitude

$$
\text { (Avg: 75\%) }
$$

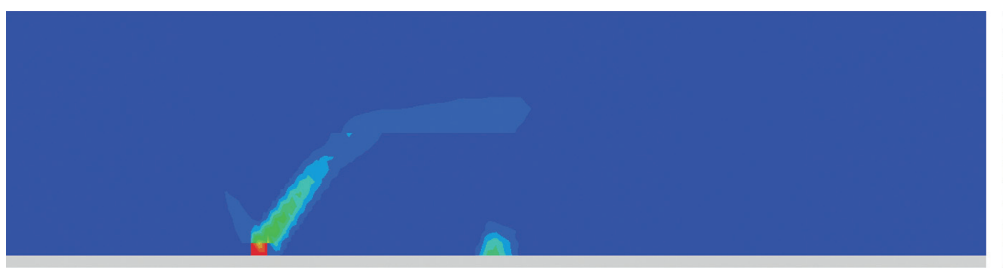

$+4.740 e-0$

$+4.345 e-01$

$+3.950 e-01$

$+3.555 e-01$

$+3.160 e-01$

$2.765 e-01$

(.

(.575e-01

$+1.580 e-01$

$+1.185 e-01$

$+7.901 e-02$

$+3.950 e-02$

(d)

Plastic strain magnitude (Avg: 75\%)

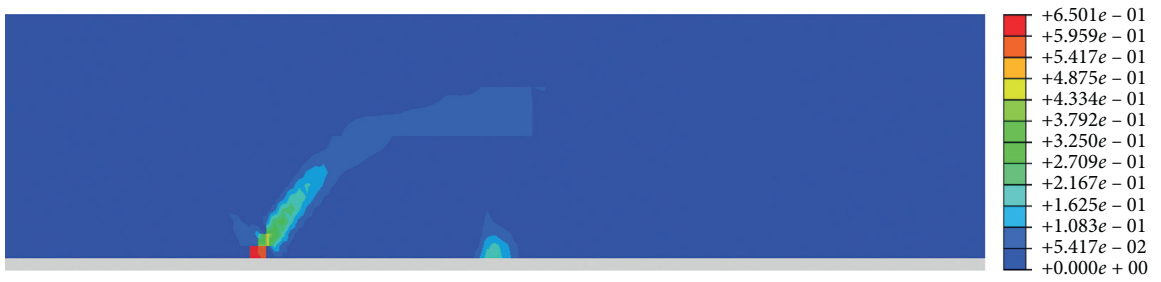

(e)

Figure 7: Continued. 


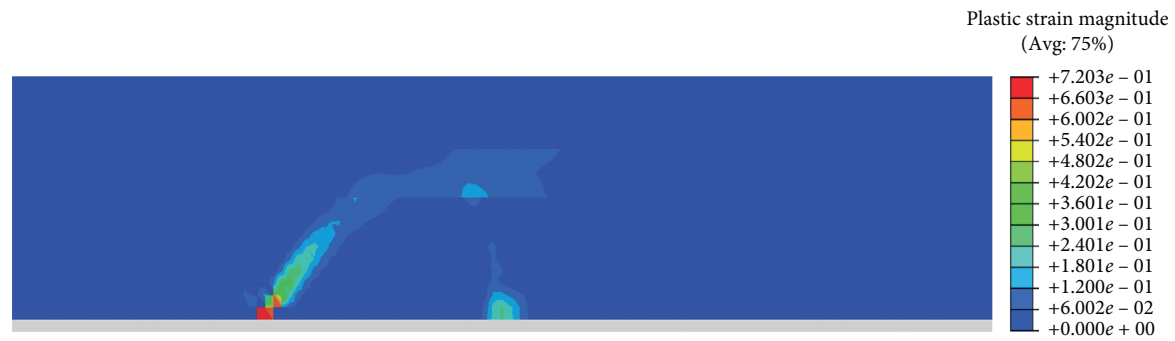

(f)

Figure 7: The cloud diagrams of the development of plastic zone under different displacements. (a) The cloud diagram of the development of a plastic zone with a displacement of $0.3 \mathrm{~m}$. (b) The cloud diagram of the development of a plastic zone with a displacement of $0.6 \mathrm{~m}$. (c) The cloud diagram of the development of a plastic zone with a displacement of $1.0 \mathrm{~m}$. (d) The cloud diagram of the development of a plastic zone with a displacement of $2.0 \mathrm{~m}$. (e) The cloud diagram of the development of a plastic zone with a displacement of $3.0 \mathrm{~m}$. (f) The cloud diagram of the development of a plastic zone with a displacement of $4.0 \mathrm{~m}$.

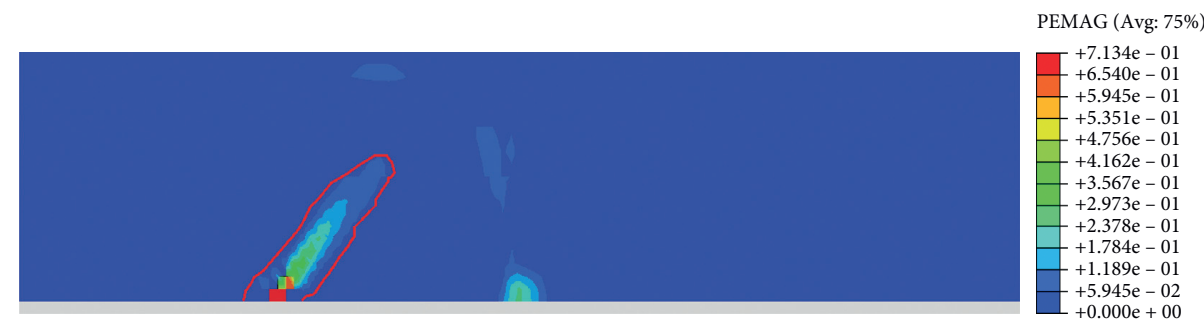

Figure 8: The cloud diagram of plastic zone of uniform round gravel soil model with a dislocation of $4.0 \mathrm{~m}$.

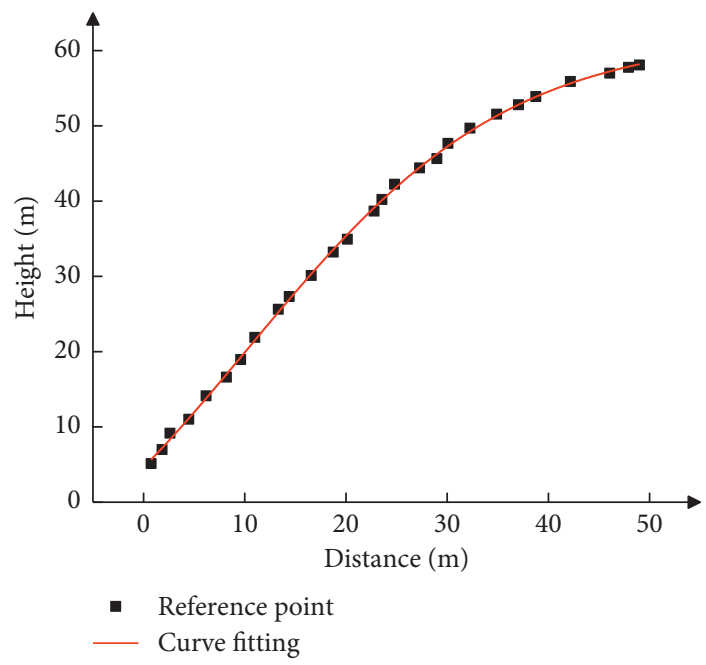

FIGURE 9: Upper envelope fitting curve of the plastic zone.

TABLE 2: Fitting curve equation and related parameters.

\begin{tabular}{lc}
\hline Equation & $y=\left(\left(A_{1}-A_{2}\right) /\left(1+e^{\left(x-x_{0}\right) / d x}\right)\right)+A_{2}$ \\
\hline$A_{1}$ & $-21.04032 \pm 3.1212$ \\
$A_{2}$ & $62.1508 \pm 0.58877$ \\
$x_{0}$ & $10.40827 \pm 0.89537$ \\
$d x$ & $12.88084 \pm 0.54026$ \\
$R^{2}(\mathrm{COD})$ & 0.99951 \\
Adjusted $R^{2}$ & 0.99945 \\
\hline
\end{tabular}

upper envelope curve of the plastic zone, reference points are selected for curve fitting according to the range of the lower envelope curve when the fracture zone is displaced $4.0 \mathrm{~m}$.
Figure 11 shows the lower envelope curve fitting curve graph, and the relevant parameters of the fitting curve are shown in Table 3.

The fitting function of the lower envelope curve in the plastic zone selects the Gauss equation. After bringing the data into the equation, the fitting curve formula of the lower envelope curve in the plastic zone is obtained. After putting the data into the equation, the following formula is obtained:

$$
y=-67.63855+\frac{1080220}{318.59067 * \sqrt{\pi / 2}} e^{-2 *\left((x-447.27807)^{2} / 318.59067^{2}\right)} .
$$




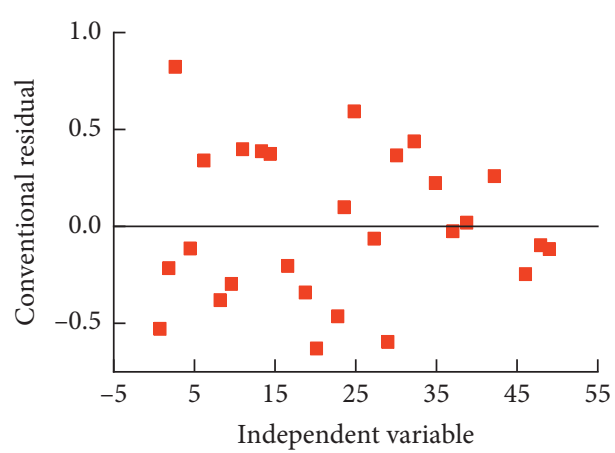

(a)

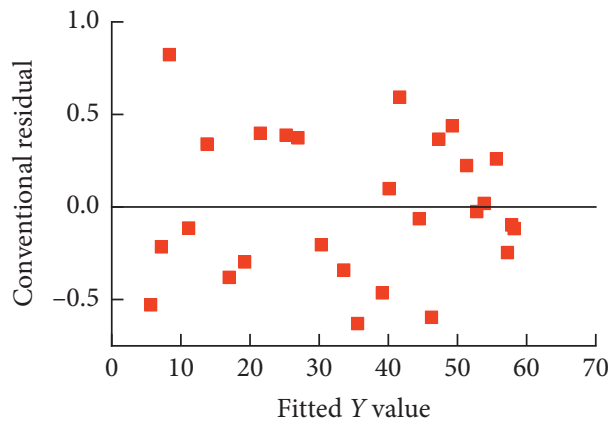

(c)

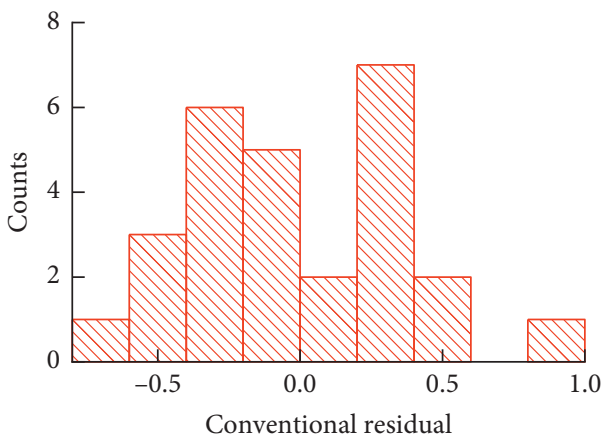

(b)

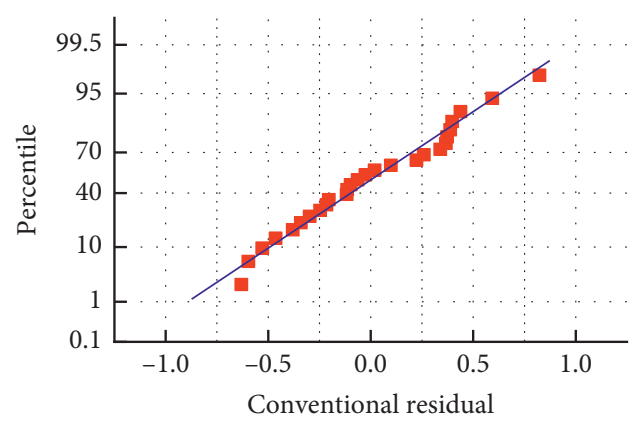

(d)

Figure 10: The residual figures of the upper envelope fitting curve.

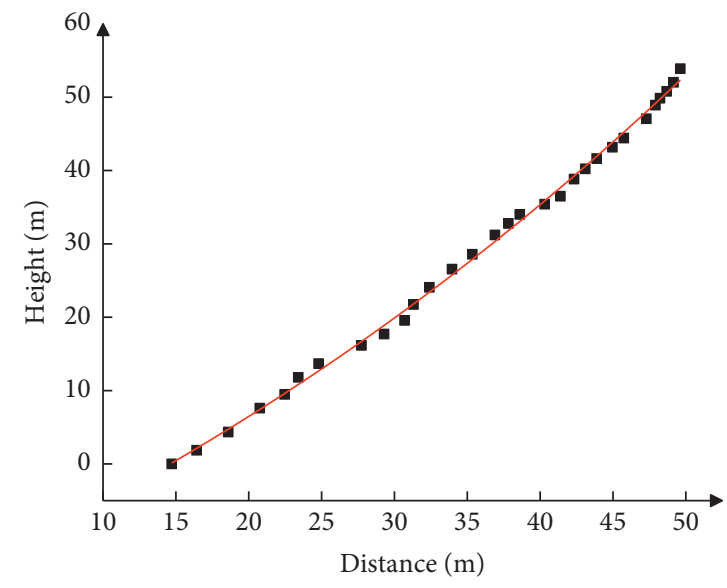

- Reference point Curve fitting

FIGURE 11: Lower envelope fitting curve of the plastic zone.

TABle 3: Fitting curve equation and related parameters.

\begin{tabular}{lc}
\hline Equation & $y=y_{0}+(A / \omega \sqrt{\pi / 2}) e^{-2 *\left(\left(x-x_{c}\right)^{2} / \omega^{2}\right)}$ \\
\hline$y_{0}$ & $-67.63855 \pm 159.72034$ \\
$x_{c}$ & $447.27807 \pm 4842.74271$ \\
$\omega$ & $318.59067 \pm 2141.81112$ \\
$A$ & $1.08022 \mathrm{E} 6 \pm 4.54252 \mathrm{E} 7$ \\
$R^{2}(\mathrm{COD})$ & 0.99784 \\
Adjusted $R^{2}$ & 0.99759 \\
\hline
\end{tabular}




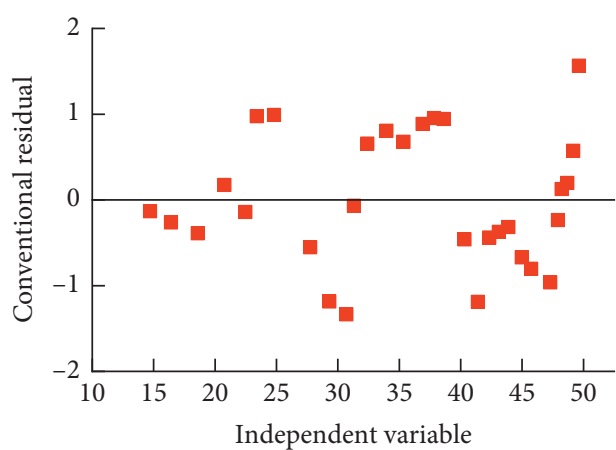

(a)

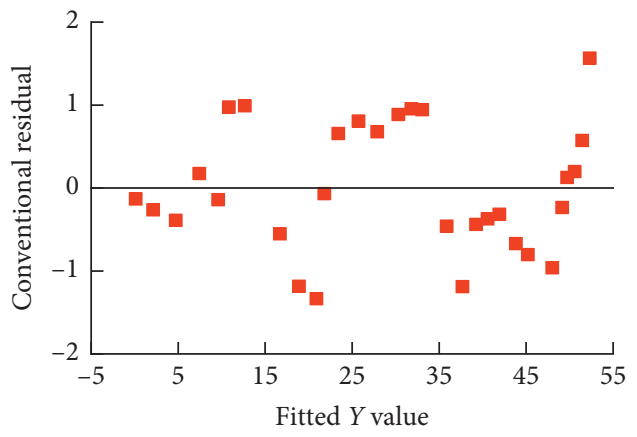

(c)

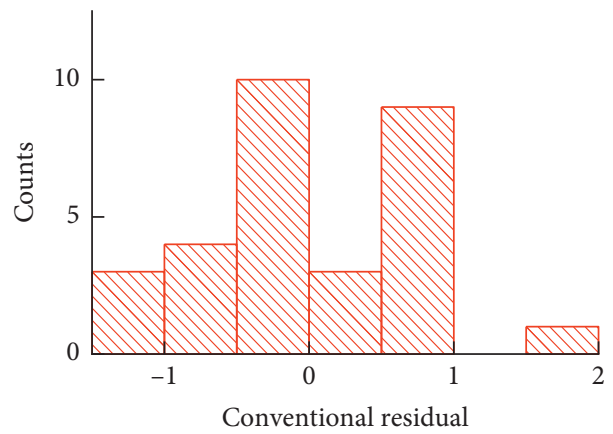

(b)

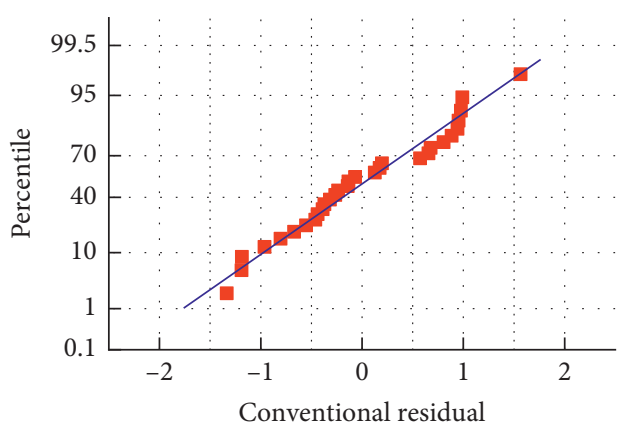

(d)

Figure 12: The residual figures of the lower envelope fitting curve.

The residual diagram of the lower envelope fitting curve is shown in Figure 12.

The correlation coefficient $R^{2}$ of the lower envelope curve fitting curve is 0.9976 , and the fitting degree of the reference points and the lower envelope fitting curve of the plastic zone is better. The points in the residual graph are distributed on a horizontal band with the origin as the center, and the distribution of scattered points along the horizontal direction is the same, indicating that the residuals are random and the selected regression model is reasonable. Therefore, it can be inferred that the development of the lower envelope of the plastic zone in the process of fracture zone dislocation satisfies the Gauss equation and exhibits a second-order exponential growth.

\section{Conclusion}

This paper uses the finite element analysis software ABAQUS to establish a three-dimensional finite element deep-site calculation model and studies the dynamic response of the deep site through the displacement distribution, stress distribution, and plastic zone distribution of the upper boundary of the overlying layer on the deep site along the longitudinal direction. At the same time, the contours of the plastic zone in the overlying soil are analyzed and fitted, and the failure mechanism of the deep site under the fault creeping dislocation is revealed. The conclusions are as follows:

(1) When creeping dislocation occurs in the bottom bedrock fracture zone, the $X$-direction deformation curve of the overlying soil is centered symmetrically at about $150 \mathrm{~m}$, and the center point is roughly located in the middle of the fracture zone. As the bottom fracture zone is squeezed to the right, the soil on the right side of the overlying layer is deformed negatively, and the soil on the left side is positively deformed. With the increase of the dislocation amount of the fracture zone, the development range of soil deformation continues to increase and finally stabilizes in the range of $0 \sim 300 \mathrm{~m}$. The $Z$-direction deformation curve is approximately symmetrically distributed around $150 \mathrm{~m}$ as the axis of symmetry, and the dislocation of the bottom fracture zone drives the overall positive deformation of the soil. As the amount of displacement of the fracture zone increases, the amount of deformation and the deformation range of the overlying soil continue to increase and stabilize in the range of $0 \sim 300 \mathrm{~m}$. Due to the large distance between the upper boundary and the bottom fracture zone, the amount of deformation gradually decreases in a disc-shaped form as the deformation propagates upward. The maximum displacement in the $Z$-direction is greater than the maximum displacement in the $X$ direction, and the deformation of the overlying soil is mainly affected by the vertical displacement of the fracture zone. The monitoring curve showed no abrupt change value, indicating that the top surface of soil did not rupture, only the influence of fault on the displacement transfer of the top surface of the soil. 
(2) When creeping dislocation occurs in the bottom fracture zone, the maximum principal stress of the upper boundary of the overlying soil layer on the deep site is dominated by compressive stress. The maximum principal stress of the soil on both sides of the fracture zone has a negative maximum value. Because the entire fracture zone is displaced to the upper right at a dip angle of $30^{\circ}$, the compression effect of the soil on the right side is significant. When the displacement of the fracture zone is less than $1.5 \mathrm{~m}$, the platform range of the maximum principal stress curve is roughly the same as the range of the fracture zone. When the displacement is greater than $1.5 \mathrm{~m}$, the range of the platform expands to $100 \sim 250 \mathrm{~m}$. The maximum principal stress monitoring curve shows a great change, indicating the development of plastic failure of soil, which is the same as the result of the plastic failure zone studied later.

(3) When the bottom fracture zone started to move, the plastic zone first appears at the junction area between the front end of the fracture zone and the overlying soil. With the increase of the amount of dislocation of the fracture zone, the plastic zone of the overlying soil begins to develop inside the overlying soil at an angle of $45^{\circ}$. After the fracture zone is displaced for a certain distance, a plastic zone begins to appear in the boundary area between its rear end and the overlying soil and extends to the upper part of the soil with the increase of the dislocation of the fracture zone, while the plastic zone at the front end extends horizontally inward. The soil on the left side of the fracture zone mainly bears the tensile force, and the right side mainly bears the pressure. The compressive strength of the soil is greater than the tensile strength, so the size of the plastic strain is concentrated in the boundary area between the front end of the fracture zone and the overlying soil and gradually decreases inward in a disc-shaped form. With the increase of the displacement amount of the fracture zone, the soil on the left shows tensile failure, and the soil on the right shows compression failure. As the amount of fault dislocation continues to increase, the soil layer contains a soft clay layer, and a plastic failure zone develops laterally, which is mainly caused by the soft clay layer's soft texture, large cohesive force, and small friction angle, which is easy to be destroyed.

(4) When the bottom fracture zone is displaced by the maximum distance, the upper envelope of the plastic zone satisfies the Boltzmann equation and exhibits a first-order exponential growth. The lower envelope satisfies the Gauss equation and exhibits a secondorder exponential growth. The development curve equation of the plastic zone is verified according to the residual figures of the fitting result and the correlation parameters.

\section{Data Availability}

All the data in this paper are available from the corresponding author upon request.

\section{Conflicts of Interest}

The authors declare that they have no conflicts of interest.

\section{Acknowledgments}

This study was supported in part by Science and Technology Research and Development Plan of China National Railway Corporation Limited (no. K2019G009), National Nature Science Fund Project (no. 52078426), Sichuan Provincial Science and Technology Support Project (nos. 2020YJ0253, 2020YFSY0060, 2019JDRC0133, and 2019JDRC0134), and China National Railway Group Co. Ltd. Scientific Research Project (nos. SY2016G003 and N2020T004).

\section{References}

[1] J. Li, S. C. Wu, Y. T. Gao, Y. L. Xie, and M. W. Ji, "Review of slope micro-seismic monitoring in open-pit mine," Chinese Journal of Rock Mechanics and Engineering, vol. 33, no. S2, pp. 3998-4013, 2014.

[2] A. W. Bishop, "The use of the slip circle in the stability analysis of slopes," Geotechnique, vol. 45, no. 1, pp. 7-17, 1995.

[3] Z. Y. Chen, "On Pan's principles of soil and rock stability analysis," Journal of Tsinghua University (Science and Technology), vol. 1, pp. 3-6, 1998.

[4] J. Lowe and L. Karaflath, "Stability of earth dams upon drawdown," in Proceedings of the 1st Panamer Conference on Soil Mechanics, pp. 537-552, Mexican Society of Soil, Guadalajara, Mexico, 1960.

[5] W. J. Guo, Study on Slope Stability of Deep Foundation Excavation Based on the Gray System Theory, Huazhong University of Science and Technology, Wuhan, China, 2005.

[6] S. Lu, "Application of multi-level fuzzy comprehensive evaluation method in stability evaluation of slope rock mass," Site Investigation Science and Technology, vol. 1, no. 4, pp. 32-37, 2014.

[7] Y. K. Sun and B. K. Yao, "Principal geological models of deformation and failure of rock slopes in China," Chinese Journal of Rock Mechanics and Engineering, vol. 2, no. 1, pp. 67-76, 1983.

[8] C. A. Soto, "A comparative study of slope modeling techniques for fractured ground," Master of Science thesis, Department of Mining and Mineral Technology, Royal School of Mines, Imperial College of Science and Technology, London, UK, 1974.

[9] J. W. Bray and R. E. Goodman, "The theory of base friction models," International Journal of Rock Mechanics and Mining Sciences \& Geomechanics Abstracts, vol. 18, no. 6, pp. 453-468, 1981.

[10] D. P. Adhykary, A. V. Dyskin, R. J. Jewell et al., "A study of the mechanism of flexural toppling failure of rock slopes," Rock Mechancis and Rock Engineering, vol. 30, no. 2, pp. 75-93, 1997.

[11] F. Sun, Z. Q. Zhang, and C. Qin, "Research on influence upon tunnel structure of metro line 1 in Urumqi forced by normal fault dislocation," China Railway Science, vol. 40, no. 2, pp. 54-63, 2019. 
[12] X. D. Ji, P. Li, S. R. Su, and Y. C. Wang, "Development and application of physical model test device showing evolution process of the reverse fault," Journal of Xi'an University of Science and Technology, vol. 33, no. 2, pp. 190-194, 2013.

[13] S. Abe, J. H. Dieterich, P. Mora, and D. Place, "Simulation of the influence of rate- and state-dependent friction on the macroscopic behavior of complex fault zones with the lattice solid model," Pure and Applied Geophysics, vol. 159, no. 9, pp. 1967-1983, 2002.

[14] S. Abe and K. Mair, "Effects of gouge fragment shape on fault friction: new 3D modelling results," Geophysical Research Letters, vol. 36, 2009.

[15] R. J. Lunn, J. P. Willson, Z. K. Shipton, and H. Moir, "Simulating brittle fault growth from linkage of preexisting structures," Journal of Geophysical Research-Solid Earth, vol. 113, no. B7, p. 10, 2008.

[16] M. T. Luan, Y. J. Wu, and T. K. Nian, “An alternating criterion based on development of plastic zone for evaluating slope stability by shear strength reduction FEM," in Proceedings of the Sina- Japanese Symposiumon Geotechnical Engineering, pp. 181-188, Geotechnical engineering in urban construction, Beijing, China, October 2003.

[17] H. Zheng, G. H. Sun, and D. F. Liu, "A practical procedure for searching critical slip surfaces of slopes based on the strength reduction technique," Computers and Geotechnics, vol. 36, pp. 1-5, 2009.

[18] S. Y. Zhao, Y. R. Zheng, and W. D. Deng, "Stability analysis on jointed rock slope by strength reduction fem," Chinese Journal of Rock Mechanics and Engineering, vol. 22, no. 2, pp. 254260, 2003.

[19] Y. R. Zheng and S. Y. Zhao, "Application of finite element strength reduction method in soil slope and rock slope," Chinese Journal of Rock Mechanics and Engineering, vol. 23, no. 19, pp. 3381-3388, 2004.

[20] L. C. Li, C. A. Tang, and J. Xing, "RFPA simulation analysis of deformation and failure of jointed rock slope," Journal of Northeastern University, vol. 27, no. 5, pp. 559-562, 2006 a.

[21] Z. Y. Chen, Y. Zhao, Analysis of tunnel response caused by active reverse fault dislocation. The Geological Society of China," in Proceedings of the 2019 National Engineering Geology Annual Conference, pp. 113-118, The Geological Society of China: Editorial Office of Journal of Engineering Geology, Beijing, China, October 2019.

[22] M. L. Lin, C. F. Chung, and F. S. Jeng, "Deformation of overburden soil induced by thrust fault slip," Engineering Geology, vol. 88, no. 1, pp. 70-89, 2006.

[23] L. Y. Zhang, Y. R. Zheng, S. Y. Zhao, and W. M. Shi, "Study on the accuracy of the finite element strength reduction coefficient method for calculating the safety factor of soil slope stability," Journal of Hydraulic Engineering, vol. 1, pp. 21-27, 2003.

[24] M. L. Lin, C. F. Chung, F. S. Jeng, and T. C. Yao, "The deformation of overburden soil induced by thrust faulting and its impact on underground tunnels," Engineering Geology, vol. 92, no. 3, pp. 110-132, 2007.

[25] J. S. Shi, Experimental and Numerical Study on the Damage of Overlying Soil and Tunnel Caused by Fault Dislocation, Zhejiang University, Zhejiang, China, 2017.

[26] H. L. Song, C. H. Zhang, and G. H. Wang, Structural Geology, Geological Publishing House, Beijing, China, 2013.

[27] M. T. Luan, Y. J. Wu, and T. K. Nian, "A criterion for evaluating slope stability based on development of plastic zone by shear strength reduction FEM," Journal of Disaster
Prevention and Mitigation Engineering, vol. 23, no. 3, pp. 1-8, 2003.

[28] G. Q. Chen, R. Q. Huang, Y. C. Shi, and Q. Xu, "Slope stability analysis based on dynamic and overall strength reduction method," Chinese Journal of Rock Mechanics and Engineering, vol. 33, no. 2, pp. 243-256, 2014.

[29] J. Jiang, G. Gao, and Y. Zhang, "Fitting of Q-S curves and bearing capacity calculation of PCC pile," Journal of China Coal Society, vol. 34, no. 4, pp. 531-532, 2009.

[30] Q. Liu and L. Yang, "New model of load transfer function for pile analysis based on disturbed state model," Journal of Tongji University (Natural Science), vol. 34, no. 2, pp. 166-168, 2006. 